\title{
Tracheal intubation
}

using a Bullard laryngo-

scope for patients with a simulated difficult airway

Kirk MacQuarrie MD FRCPC, Orlando R. Hung MD FRCPC, J. Adam Law MD FRCPC

Purpose: To evaluate the utility and safety of orotracheal intubation in adult patients with simulated difficult airways using the Bullard Laryngoscope (BL).

Methods: A rigid cervical collar was used to simulate the difficult airway. The study consisted of two phases. Phase I evaluated the BL used in conjunction with an independently styletted endotracheal tube (ISETT) passed freehand into the trachea. Phase II evaluated the new Multifunctional Intubating Stylet (MFIS). Forty patients were studied in each phase. Following induction of anesthesia a rigid cervical collar was applied and the laryngoscopic grade assessed. Tracheal intubation was then performed using the BL with either an ISETT or the MFIS. The total time to intubate, number of attempts, failures, hemodynamic changes during intubation were recorded.

Results: The rigid collar effectively simulated a difficult laryngoscopy, $65 \%$ of patients had a grade 3 view. The success rates for tracheal intubation using the ISETT and MFIS were $88 \%$ and $83 \%$ respectively. The average times to intubation were similar for both intubating techniques ( $45.4 \pm 26.8 \mathrm{sec}$ for the ISETT and 4I.2 \pm 25.2 $\mathrm{sec}$ for the MFIS). Although there were minor hemodynamic changes, mucosal bleeding and sore throat following intubation, there were no major complications in any of the study patients.

Conclusions: The BL, used with either an ISETT or the MFIS, is an effective and safe intubating device for patients with simulated restricted cervical spine movement. Further studies are needed to compare the effectiveness and safety of these two techniques in managing patients with a difficult airway.

Objectif : Évaluer l'utilité et la sécurité de l'intubation orotrachéale de patients adultes, chez qui on a simulé une altération des voies aériennes, en utilisant un laryngoscope de Bullard (LB).

Méthode : Un collier cenvical rigide a été utilisé pour simuler l'intubation difficile. Quarante patients ont participé à chacune des deux phases de l'étude : pendant la phase I, on a évalué le LB utilisé en conjonction avec un tube endotrachéal à stylet indépendant (TETSI) passé à main libre dans la trachée; pendant la phase II, on a évalué le nouveau stylet d'intubation multifonctionnel (SIMF). Après l'induction de l'anesthésie, on a appliqué un collier cervical rigide et coté la laryngoscopie. On a procédé ensuite à l'intubation en utilisant le LB soit avec le TETSI, soit avec le SIMF. Le temps total nécessaire pour procéder à l'intubation, le nombre d'essais, les échecs et les changements hémodynamiques qui se sont produits pendant l'intubation ont été notés.

Résultats: Le collier rigide a efficacement simulé des difficultés d'intubation, $65 \%$ des patients présentant une classe 3. Les taux de réussite de l'intubation endotrachéale avec le TETSI ou le SIMF ont été de $88 \%$ et $83 \%$ respectivement. Les deux techniques d'intubation ont nécessité des temps similaires ( $45,4 \pm 26,8 \mathrm{~s}$ avec le TETSI et $41,2 \pm 25,2 \mathrm{~s}$ avec le SIMF). Des changements hémodynamiques mineurs sont survenus, un saignement de la muqueuse et une irritation de la gorge après l'intubation, mais aucune complication importante.

Conclusion : Le LB, utilisé avec un TETSI ou le SIMF, est un dispositif d'intubation efficace et sécuritaire pour les patients dont les mouvements simulés de la colonne cervicale sont limités. Des études supplémentaires sont cependant nécessaires pour comparer l'efficacité et la sécurité de ces deux techniques chez des patients pour qui l'intubation est difficile.

From the Department of Anesthesia, Dalhousie University, Queen Elizabeth II Health Sciences Centre, Victoria General Site, 1278 Tower Road, Halifax, Nova Scotia, Canada B3H 2 Y9.

Address correspondence to: Dr. Kirk MacQuarrie, Phone: 902-473-2331; Fax: 902-423-9454; E-mail: kmacquar@is2.dal.ca Accepted for publication April 25, 1999 


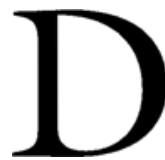

ESPITE advances in airway management, there is no single best technique to intubate the trachea of patients with a difficult airway. The Bullard Laryngoscope (Circon ACMI, Stamford, CT) has been described as a potentially useful alternative for intubation in these patients. ${ }^{1}$ The Bullard Laryngoscope (BL) consists of a rigid, right-angled blade with a fibreoptic viewing system. The design of the scope allows visualization of the glottis without aligning the oral, pharyngeal and laryngeal axes during tracheal intubation. This decreases cervical spine movement compared with tracheal intubation with the Miller ${ }^{2}$ or MacIntosh ${ }^{2,3}$ laryngoscopes. The BL can be used to perform orotracheal or nasotracheal intubation ${ }^{4}$ in anesthetized and awake patients, ${ }^{5-10}$ in the adult or pediatric age groups. ${ }^{5,11}$ With some exceptions ${ }^{4,8,12}$ studies of orotracheal intubation using the $\mathrm{BL}$ in adults with difficult airways have been limited to case reports involving small numbers of patients. ${ }^{6,7,9,10,13}$

The BL provides good visualization of the glottis. However, it is occasionally difficult to advance the endotracheal tube through the glottic opening using the device. A number of techniques to facilitate orotracheal intubation with the BL have evolved, either reported by users or developed by the manufacturer. These include: 1) an independently styletted endotracheal tube (ISETT) passed freehand into the trachea; 2) a dedicated stylet which is attached to the BL; and 3) a new wider, hollowed Multifunctional Intubating Stylet (MFIS) which also attaches to the BL. The MFIS guides the insertion of an intubating catheter into the trachea, over which an endotracheal tube (ETT) is advanced into the glottis and trachea. The MFIS has only recently been introduced, and its effectiveness has not been determined.

The present study evaluated the use of the $\mathrm{BL}$ in patients with a simulated difficult airway using a rigid cervical collar in two phases. The goal of the Phase I Study was to determine the safety and utility of the BL with an ISETT for orotracheal intubation. Under similar conditions, the Phase II Study involved the use of BL with the MFIS, which became available while we were conducting the Phase I Study.

\section{Methods}

Institutional review board approval was obtained and all study patients gave informed consent. ASA class I and II patients scheduled for elective surgery under general anesthesia requiring tracheal intubation were recruited. Patients were excluded from the study if they required awake tracheal intubation, or rapid sequence induction of anesthesia. All tracheal intubations were performed by one of three investigators experienced with the use of the BL. Each of the investigators had previously performed more than 25 intubations with the BL.

Airway assessment, including measurement of mouth opening, was carried out during the pre-operative anesthetic evaluation for all study patients. Upon arrival at the operating room, monitors placed included a pulse oximeter, electrocardiogram and non-invasive blood pressure cuff. Baseline vital signs, including blood pressure and heart rate were obtained. Denitrogenation was performed for three minutes prior to the induction of anesthesia. General anesthesia was induced with $1.5-2.5 \mathrm{mg} \cdot \mathrm{kg}^{-1}$ propofol supplemented by $1.5-3 \mu \mathrm{g} \cdot \mathrm{kg}^{-1}$ fentanyl or 0.15 to $0.3 \mu \mathrm{g} \cdot \mathrm{kg}^{-1}$ sufentanil $i v$. After confirmation of effective mask ventilation, muscle relaxation was achieved using either $0.1-0.15$ $\mathrm{mg} \cdot \mathrm{kg}^{-1}$ vecuronium or $1.5 \mathrm{mg} \cdot \mathrm{kg}^{-1}$ succinylcholine. A rigid cervical collar (Aspen Rehabilitation Collar, International Health Care Devices, Long Beach, CA) of appropriate size was then applied. Mouth opening was again measured and direct laryngoscopy was performed using a size \#3 Macintosh blade. Laryngoscopic view was graded as described by Cormack and Lehane. ${ }^{14}$ No laryngeal manipulation was used during grading. Following application of anti-fog solution tracheal intubation was then performed using the BL with either an ISETT or the MFIS. Size \#7.0 ETT was used for all female patients, while size \#7.5 was used for men. A commercially available blade extender (Circon ACMI, Stamford, CT) was used for male patients and for large women. Three intubation attempts were allowed with ventilation and oxygenation interposed. Attempted tracheal intubation using the $\mathrm{BL}$ was terminated if the patient showed signs of oxygen desaturation or if it was felt by the anesthesiologist that further attempts would be unsafe and/or futile. In the event of a failure, the collar was removed and tracheal intubation was performed under direct laryngoscopy. Blood pressure and heart rate were recorded every $30 \mathrm{sec}$ following induction and for five minutes post-intubation.

The time to intubate during each attempt was defined as the time from the insertion of the BL into the oral cavity to its removal. Total time to intubate (TTI) was defined as the summation of time to intubate for all attempts. The TTI and number of attempts and failures were recorded. The maximal changes in mean blood pressure (MAP) and heart rate (HR) were calculated by subtracting the peak MAP and HR following intubation from the baseline (pre-induction) measurements.

Following tracheal intubation, the rigid cervical collar was removed to allow inspection of the oropharynx using a laryngoscope for evidence of trauma or mucosal bleeding. After extubation at the end of 
surgery, the nurses in the Post Anesthetic Care Unit, who were unaware of the intubation technique, were instructed to ask the patients for complaints of sore throat prior to discharge from the unit.

\section{Results}

Eighty patients were studied with 40 in each study phase. Patient demographics are summarized in Table I. The majority of the study patients were female $(66 \%)$, undergoing laparoscopy or laparotomy. Degree of mouth opening before and after collar application, and the post collar application laryngoscopic view on direct and Bullard laryngoscopy are shown in Table II. With the application of the rigid cervical collar $98 \%$ of patients had a grade 2 or higher laryngoscopic view and $65 \%$ of patients presented with a grade 3 view. The epiglottis could be visualized in all patients, thus there were no grade 4 views.

Total time to intubate, number of attempts, failures, trauma and hemodynamic changes associated with tracheal intubation using both techniques are shown in Table III. There were 12 failures, seven in the MFIS and five in the ISETT group. The success rates of ISETT and MFIS intubations were $88 \%$ and $83 \%$ respectively. The combined success rate was $85 \%$. Poor visualization, secondary to either fogging or secretions, was the reason for six of the failures. Three of the failures in the MFIS group were secondary to inability to advance the ETT despite passage of the intubating catheter into the trachea. The remainder of the failures were due to an inability to manipulate the ISETT or MFIS into the hypopharynx due to a restricted mouth opening. Tracheal intubation for these patients was easily achieved by direct laryngoscopy once the collar was removed. The average times to intubation were similar for both intubating techniques (45.4 $\pm 26.8 \mathrm{sec}$ for the ISETT and $41.2 \pm$ $25.2 \mathrm{sec}$ for the MFIS). Patients who had a failed BL intubation were not included in determinations of either mean total time to intubation or hemodynamic changes following intubation.

Oral trauma was limited to mild mucosal bleeding. None of the study patients had major complications

TABLE I Patient Demographics

\begin{tabular}{lll}
\hline & ISETT & MFIS \\
\hline Number of Patients & 40 & 40 \\
Male/Femalc & $14 / 26$ & $13 / 27$ \\
Age (yr) & $53.3 \pm 15.6$ & $50.3 \pm 16.9$ \\
Weight $(\mathrm{Kg})$ & $78.3 \pm 18.4$ & $74.7 \pm 16.7$ \\
Height $(\mathrm{cm})$ & $166.5 \pm 9.5$ & $163.8 \pm 9.4$ \\
\hline
\end{tabular}

All data expressed as mean $\pm \mathrm{SD}$
TABLE II Laryngoscopic grade, and mouth opening with and without collar

\begin{tabular}{lll}
\hline & ISETT & MFIS \\
\hline Laryngoscopic Grade $\dagger$ & & \\
I. Entire glotris visible & 2 & 0 \\
II. Only posterior glottis visible & 13 & 13 \\
III. Only epiglottis visible & 25 & 27 \\
IV. Unable to even view epiglottis & 0 & 0 \\
Mouth opening without collar $(\mathrm{cm})^{*}$ & $4.7 \pm 0.7$ & $4.7 \pm 0.5$ \\
Mouth opening with collar(cm) & $2.3 \pm 0.6$ & $2.6 \pm 0.5$ \\
\hline
\end{tabular}

* data expressed as mean (standard deviacion)

† From Cormack and Lehanc ${ }^{14}$

TABLE III Results

\begin{tabular}{lll}
\hline & ISETT & MFIS \\
\hline Attempts $(1 / 2 / 3)$ & $35 / 5 / 1$ & $36 / 4 / 0$ \\
Failures & 5 & 7 \\
Mean total time to intubate (sec) * & $45.5 \pm 26.8$ & $41.2 \pm 25.2$ \\
Range of total time to intubate (sec) & $19-140$ & $15-108$ \\
Trauma & 12 & 19 \\
Sore throat & 17 & 21 \\
Change in MAP from baseline $(\%)^{*}$ & $-5.3 \pm 23.6$ & $-1.2 \pm 19.2$ \\
Change in HR from baseline $(\%)^{*}$ & $+5.4 \pm 22.3$ & $+14.2 \pm 21.0$ \\
\hline
\end{tabular}

* data expressed as mean $\pm \mathrm{SD}$

following tracheal intubation. There were clinically insignificant hemodynamic changes following tracheal intubation using the two techniques: in the ISETT and MFIS groups, heart rate increased an average of $5 \%$ and $14 \%$ respectively, and blood pressure decreased by $1 \%$ and $5 \%$ respectively (Table III). The incidence of sore throat was similar in each group: $43 \%$ in the ISETT, and $53 \%$ in the MFIS group.

\section{Discussion}

We have previously described the use of a rigid cervical collar as a method of simulating difficult intubating conditions using the gum elastic bougie. ${ }^{15}$ This study further confirms that a properly applied rigid cervical collar can effectively simulate a difficult airway situation, with over $50 \%$ of patients in both studies being grade III (epiglottis only) on direct laryngoscopy. The anatomical determinants of the grade III laryngoscopies in this model are a combination of decreased jaw opening (by almost $50 \%$ ) and decreased neck mobility. This is the first prospective study to evaluate the use of the Bullard laryngoscope to intubate orally a series of adult patients with known (albeit simulated) difficult airways. It is also the first study to evaluate the use of the new MFIS. 
Six of the 12 failures to intubate with the BL were caused by fogging and/or secretions. Aggressive attention to application of an anti-fog solution to the end of the fibreoptic bundle, together with warming of the laryngoscope blade before use (with a warm blanket, warm water, or forced air heater ${ }^{16}$ ) can help to minimize this well known potential problem with any fibreoptic intubating technique. In addition, application of high flow $\left(8-15 \mathrm{l} \cdot \mathrm{min}^{-1}\right) \mathrm{O}_{2}$ through the suction port (not done in this study) has been described as another, effective method to minimize problems with both secretions and fogging. ${ }^{9,17}$

The second cause of failure to intubate (three patients in the MFIS group) was an inability to advance the ETT over the MFIS intubating catheter into the glottis, in spite of the successful passage of the intubation catheter through the glottic opening. This problem was caused by the impingement of the ETT

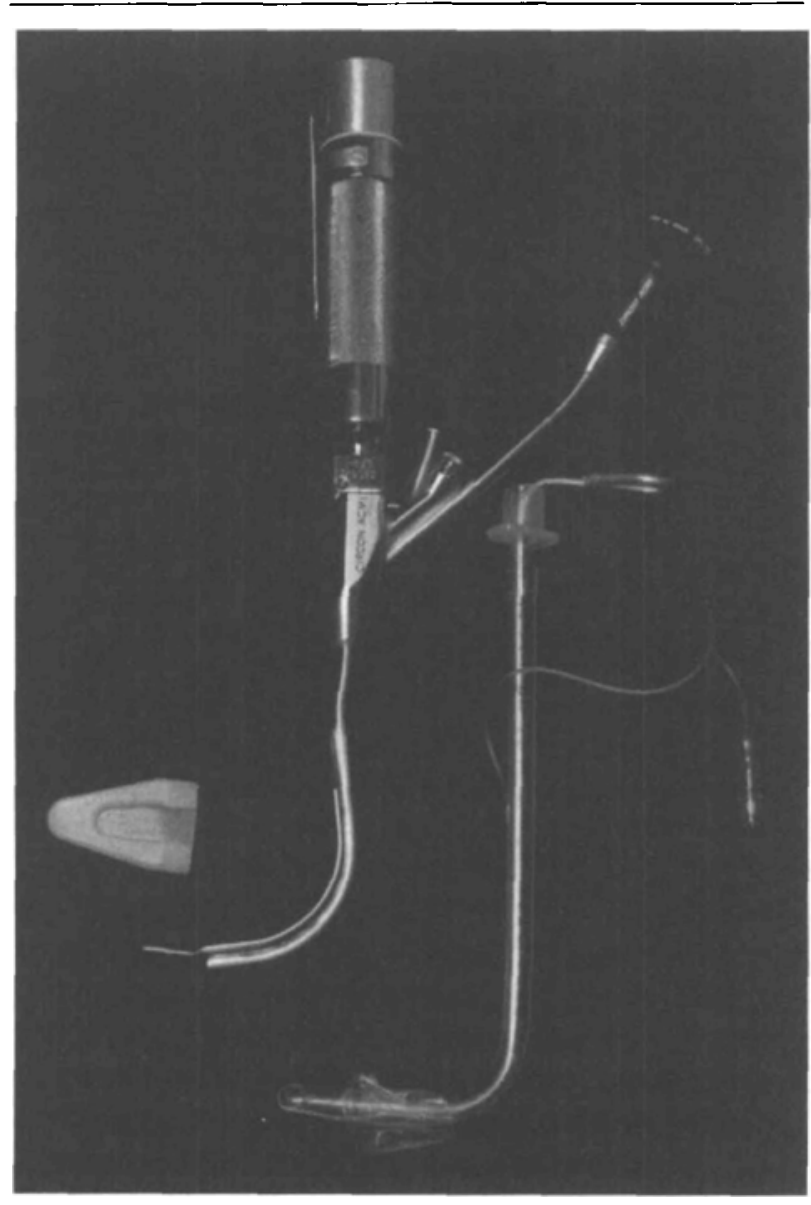

FIGURE 1 The Bullard Laryngoscope is shown together with an independently styletted endotracheal tube. The Styletted endotracheal tube is bent 90 at the distal end to conform to the shape of the Bullard Laryngoscope blade. Notc the blade tip extender is detached from the Bullard Laryngoscope. on either the right aryepiglottic fold, arytenoid cartilage or vocal cord. This is similar to the reported problems associated with the dedicated attached stylet of the BL. ${ }^{10,18}$ The new MFIS was designed, in part, to avoid these problems. However, our data showed that these problems may persist in spite of the presence of a guiding catheter in the trachea. Potential solutions to this problem include a 180 rotation of the ETT on the stylet, moving the loaded laryngoscope 2$3 \mathrm{~mm}$ to the left of the vocal cords and, with the older stylet, reducing the degree of terminal angulation of the stylet. ${ }^{17,18}$ The third and final cause of failed intubation in this study was the difficulty in manipulating the BL and ETT within the oral cavity in the setting of limited mouth opening. While only $0.6 \mathrm{~cm}$ of

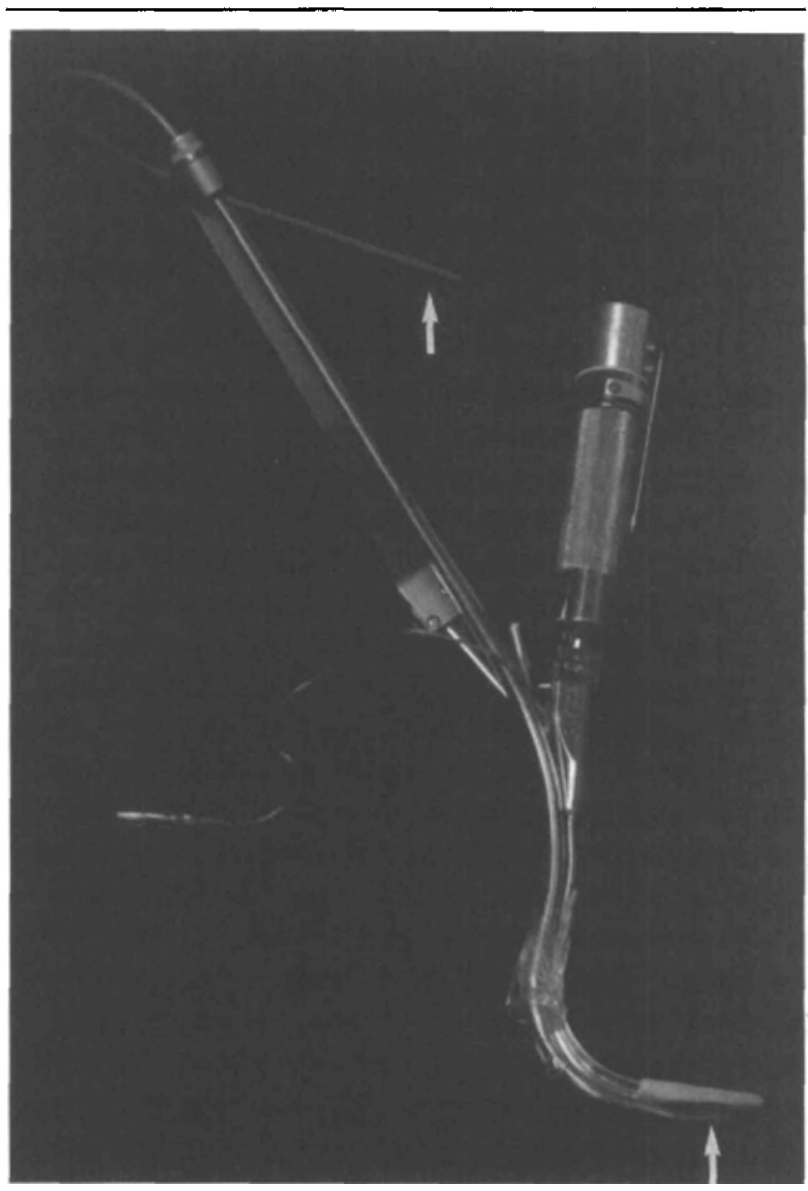

FIGURE 2 The mulcifunctional intubating stylet (MFIS) is attached to the Bullard Laryngoscope with a blade tip extender. Loaded onto the MFIS is an endotracheal tube. The flexible intubating catheter (arrows) can be seen extending from both ends of MFIS. Following the placement of the inrubating catheter in the trachea, the endotracheal tube advances over the catheter. The entire unit, including the intubating catheter is then withdrawn from the oropharynx. 
mouth opening is required for successful BL blade insertion into the oral cavity, passage of the ETT, with either the ISETT or MFIS technique, requires a substantially wider mouth opening. We found, during the course of the study, that positioning the ETT proximally on the MFIS, and using a smaller ETT (7.0-7.5 ID) will aid the passage through the oropharynx and minimize the displacement of the end of the stylet from the view through the scope. Our experience raises concerns that the BL may be difficult to use in patients with a restricted mouth opening. Conversely, while a rigid cervical collar can simulate a difficult airway for many intubating techniques, the restricted mouth opening after its application may render the model unsuitable for evaluating the Bullard laryngoscope. Perhaps, the "low" success rate for both techniques ( $88 \%$ for ISETT and $83 \%$ for MFIS) is partially a reflection of the choice of this difficult airway model.

Other published series of BL intubations report a success rate similar to ours. Borland $e t$ al. reported a 93\% success rate by using the BL with an ISETT to intubate the tracheas of children with difficult airway. ${ }^{5}$ Cooper et al. reported a $\mathbf{9 6 \%}$ success rate in $\mathbf{5 0}$ adult elective surgical patients using the dedicated intubating stylet ${ }^{19}$ however only seven of these patients were classified as having a grade III laryngoscopic view. Shigematsu $e t$ al. reported success in 26 adult patients with a history of difficult airways, using the BL with a flexible tip ETT to intubate their patients nasally. ${ }^{4}$ The nasal route may overcome some of the problems of insertion and manipulation of the ETT within the oropharynx but is not without potential complications, such as bleeding. Other reports are limited to case studies involving only small numbers of patients. $6,7,9,10,13$

Although this study was not designed to compare the two intubating methods, our data showed similar times to perform tracheal intubation using the two intubating techniques. However, it should be emphasized that evaluation of the MFIS occurred after the first 40 intubations using the ISETT. Although the three investigators were experienced with the use the BL before the study, it is possible that the investigators had gained considerable experience using the $\mathrm{BL}$ in the presence of a rigid cervical collar. This learning curve may have influenced the intubation time using the MFIS.

Our data have shown that hemodynamic changes following BL intubation using either technique were comparable to changes associated with intubation using conventional laryngoscopy. ${ }^{20}$ However, future comparative studies are necessary to determine the differences in hemodynamic effects of tracheal intubation using the BL and direct laryngoscopy. Although there was no dental injury observed in this study, many patients had small amounts of bleeding from the oropharyngeal mucosa following intubation. In the study by Cooper et al. ${ }^{9}$ the ISETT technique was abandoned because of concerns regarding excessive mucosal bleeding. We did not find this to be major problem. In fact we observed less bleeding in the ISETT group (30\%) than in the MFIS group (48\%). Cooper examined the use of the dedicated intubating stylet which is different than the MFIS used in our study, and may perhaps cause less bleeding. There was no evidence of mucosal laceration on examination of the oropharynx under direct laryngoscopy following intubation. It should be emphasized that small amounts of mucosal bleeding are relatively common with any airway manipulation, particularly in a difficult airway situation. Our overall incidence of sore throat as determined by direct questioning was $48 \%$, comparable to other intubating techniques including direct laryngoscopy. Sore throat is a common finding following general anesthesia and is possibly related to multiple factors. The quoted incidence ranges widely from $5-100 \%{ }^{21}$

With the use of a blade extender in selected patients (male and larger patients), there was no difficulty in lifting the epiglottis during intubation. Prior to tracheal intubation in this group of patients, it is important that the blade extender is properly placed at the tip of the BL blade by listening and feeling for a firm "snap". This will minimize the risk of detachment of the blade extender from the BL blade during tracheal intubation: a potential cause of airway obstruction.

During preparation for $\mathrm{BL}$ intubation using the MFIS, it was our preference to disconnect the $15 \mathrm{~mm}$ ETT adapter (Figure 2). This allows easier advancement of the ETT over the MFIS into the trachea. The time needed for adapter reattachment was not included in the total time to intubate.

In summary, this study demonstrated that the Bullard Laryngoscope together with either an independently styletted endotracheal tube passed freehand into the trachea or the new Multifunctional Intubating Stylet is an effective and safe intubating device for patients with a simulated restriction in cervical spine movement. While the study was not designed to compare the MFIS with the ISETT/freehand technique directly, our results suggested similar success rates, times to intubation and safety of both techniques. In the hands of experienced users of the $\mathrm{BL}$, it is our impression that the MFIS has no apparent advantages over the ISETT, and was certainly more cumbersome to use and clean. Further studies are needed to compare the effectiveness and safety of these two techniques in managing patients with a history of difficult airway. 


\section{References}

1 Cooper SD. The evolution of upper-airway retraction: new and old laryngoscopy blades. In: Benumof JL (Ed.). Airway Management. Principles and Practice. St. Louis: Mosby, 1996: 374-411.

2 Hastings RH, Vigil AC, Hanna R, Tang B-H, Sartoris $D J$. Cervical spine movement during laryngoscopy with the Bullard, MacIntosh, and Miller laryngoscopes. Anesthesiology 1995; 82: 859-69.

3 Watts ADJ, Gelb AW, Bach DB, Pelz DM. Comparison of the Bullard and Macintosh laryngoscopes for endotracheal intubation of patients with a potential cervical spine injury. Anesthesiology 1997; 87: 1335-42.

4 Shigematsu $T$, Miyazawa $N$, Kobayashi $M$, Yorozu $T$, Toyoda $\Upsilon$, Morisaki $H$. Nasal intubation with the Bullard laryngoscope: a useful approach for difficult airways. Anesth Analg 1994; 79: 132-5.

5 Borland $L M$, Casselbrant $M$. The Bullard laryngoscope. A new indirect oral laryngoscope (pediatric version). Anesth Analg 1990; 70: 105-8.

6 Cobn AI, McGraw SR, King WH. Awake intubation of the adult trachea using the Bullard laryngoscope. Can J Anaesth $1995 ; 42: 246-8$.

7 Cobn AI, Hart RT, McGraw SR, Blass NH. The Bullard laryngoscope for emergency airway management in a morbidly obese parturient. Anesth Analg 1995; 81: 872-3.

8 Cobn AI, Zornow MH. Awake endotracheal intubation in patients with cervical spine disease: a comparison of the Bullard laryngoscope and the fiberoptic bronchoscope. Anesth Analg 1995; 81: 1283-6.

9 Ghouri AF, Bernstein CA. Use of the Bullard laryngoscope blade in patients with maxillofacial injuries (Letter). Anesthesiology 1996; 84: 490.

10 Gorback MS. Management of the challenging airway with the Bullard laryngoscope. J Clin Anesth 1991; 3: 473-7.

11 Shulman GB, Connelly NR, Gibson C. The adult Bullard laryngoscope in paediatric patients. Can J Anaesth 1997; 44: 969-72.

12 Saunders PR, Geisecke AH. Clinical assessment of the adult Bullard laryngoscope. Can J Anaesth 1989; 36: S118-9.

13 Midttun M, Hansen CL, Jensen K, Pedersen T. The Bullard laryngoscope. Reports of two cases of difficult intubation. Acta Anaesthesiol Scand 1994; 38: 300-30.

14 Cormack RS, Lebane J. Difficult tracheal intubation in Obstetrics. Anaesthesia 1984; 39: 1105-11.

15 McNeil P, Hung OR. Tracheal intubation using a Gum Elastic Bougie for patients with restricted cervical spine movement. Can J Anaesth 1996; 43: A26.

16 Dunn SM, Pulai I. Forced air warming can facilitate fiberoptic intubations (Letter). Anesthesiology 1998; 88: 282.
17 Crosby ET. Techniques using the Bullard laryngoscope (Letter). Anesth Analg 1995; 81: 1314.

18 Katsnelson T, Farcon E, Schwalbe SS, Badola R. The Bullard laryngoscope and the right arytenoid (Letter). Can J Anaesth 1994; 41: 552-3.

19 Cooper $S D$, Benumof $J L, O z a k i$ GT. Evaluation of the Bullard laryngoscope using the new intubating stylet: comparison with conventional laryngoscopy. Anesth Analg 1994; 79: 965-70.

20 Shribman AJ, Smith G, Achola KJ. Cardiovascular and catecholamine responses to laryngoscopy with and without tracheal intubation. Br J Anaesth 1987; 59: 295-9.

21 Finucane BT, Santora $A H$. Principles of Airway Management, 2nd ed. St. Louis: Mosby, 1996. 